\title{
O DESAFIO DA IMPLEMENTAÇÃO DA EDUCAÇÃO PERMANENTE NA GESTÃO DA EDUCAÇÃO NA SAÚDE
}

\author{
THE CHALLENGE OF IMPLEMENTING CONTINUING EDUCATION IN HEALTH EDUCATION \\ MANAGEMENT
}

EL RETO DE IMPLEMENTAR LA EDUCACIÓN PERMANENTE EN LA GESTIÓN DE LA EDUCACIÓN

EN SALUD

\author{
Neuza Buarque de Macêdo ${ }^{1}$ \\ Paulette Cavalcanti de Albuquerque ${ }^{2}$ \\ Kátia Rejane de Medeiros ${ }^{3}$
}

Resumo O caminho utilizado neste estudo foi a revisão sistemática de literatura da produção científica e do marco normativo, com o objetivo de identificar as principais concepções teórico-conceituais referentes à gestão da educação na saúde no Brasil no período de 2003 a 2009. A gestão do Sistema Único de Saúde aponta para a necessidade de qualificação de gestores e profissionais para atuar no setor desde a graduação, incluindo a integração ensino-serviço e a formação profissional no ambiente de trabalho. Após a aplicação de critérios de inclusão, 16 artigos e seis portarias foram incluídos na revisão. No âmbito da gestão da educação na saúde, o debate gira em torno de duas principais concepções, a educação continuada e a educação permanente, centradas respectivamente no modelo acadêmico e na aprendizagem em equipe, inerente aos grupos de trabalhadores. A análise da produção científica e do marco normativo sugere que as transformações conceituais desafiam todos os atores da saúde a realizarem uma ruptura teórico-conceitual e de posicionamento subjetivo, superando uma posição de 'recurso humano', realizador de tarefas, para a de sujeito capaz de refletir sobre os processos de trabalho.

Palavras-chave formação de recursos humanos; qualificação profissional; gestão em saúde.
Abstract This study undertook a systematic review of the scientific literature and of the regulatory framework to pinpoint key theoretical and conceptual ideas on health education management in Brazil in the period of 2003-2009. The management of the National Health System points to the need of training managers and professionals to work in the industry from the moment they graduate, including teaching-service integration and professional training in the workplace. After applying the inclusion criteria, 16 articles and six ordinances were included in the review. Insofar as health education management is concerned, the debate revolves around two main concepts, permanent education and continuing education centered, respectively, on the academic model and in team learning, inherent to the groups of workers. The analysis of the scientific literature and of the regulatory framework suggests that conceptual transformations challenge all players in health to a theoretical-conceptual break away and subjective stance, extending beyond a position of 'human resource,' undertaker of tasks, and reaching a subject capable of reflecting on the work processes.

Keywords training of human resources; professional qualifications; health management. 


\section{Introdução}

O Brasil, ao longo dos anos 1980, recuperou as bases de uma estrutura de Estado federativo, o que repercutiu numa redistribuição de poder entre os três níveis de governo (União, estados e municípios), implicando uma mudança na autonomia política e nas funções administrativas dos governos locais, funções centradas anteriormente na esfera federal. Essa transformação institucional que foi se operacionalizando no Sistema Brasileiro de Proteção Social aconteceu com muitas variações, tanto entre as diferentes políticas quanto entre os estados brasileiros (Arretche, 2002), havendo, assim, um descompasso entre a descentralização e a efetiva gestão local das políticas sociais (processo de municipalização).

A descentralização das políticas sociais sinaliza, mais amplamente, para a necessidade de reorganização dos sistemas locais de gestão que, em conjunto com a intersetorialidade, determinariam uma nova forma de gestão das cidades mais relacionada à população e seus agravos, vinculados ao território ou região (Pierantoni, 2001). Nesse sentido, na experimentação prática em planejamento e organização de serviços de saúde, os gestores municipais vêm se constituindo como importantes atores sociais no cenário político-institucional do Sistema Único de Saúde (SUS) (Cecílio et al., 2007).

Porém, há que se reconhecer a diversidade existente entre os gestores municipais, predominando inexperiência e falta de formação na gestão da 'coisa pública'; inexistência de uma 'equipe de governo' com capacidade para planejar, implantar políticas e avaliar os impactos da gestão em saúde; não utilização de indicadores para conhecimento das necessidades de saúde da população e posterior organização da gestão (Cecílio et al., 2007). Nesse contexto, o modelo assistencial está centrado nas consultas especializadas e procedimentos, sem reconhecer grupos prioritários e desenvolver ações regulares, programadas, educativas e por equipes multiprofissionais (Paim e Teixeira, 2007). Compreender as especificidades das organizações públicas que produzem serviços de saúde em razão de seus elementos constitutivos, da sua forma de funcionar e de seus problemas específicos é essencial para que se possa fazer uma reflexão sobre qual a melhor maneira de organizar e gerir os serviços de saúde (Dussault, 1992).

No âmbito do SUS, existe um consenso de que a política de recursos humanos é uma dimensão estratégica da gestão em saúde, na medida em que o setor se caracteriza por ter mão de obra intensiva, com expressivo contingente de trabalhadores, cuja incorporação de recursos tecnológicos e equipamentos não implica redução do número de contratações (Conselho Nacional de Secretários de Saúde, 2007).

Contudo, a questão de recursos humanos na área da saúde nem sempre foi foco de preocupação dos gestores públicos. A sua gestão e o seu planeja- 
mento eram realizados de forma muito fragmentada entre o Ministério da Saúde (MS), a Secretaria de Assistência à Saúde e o Instituto Nacional de Assistência Médica da Previdência Social (Inamps). O foco de atuação se dava na organização da rede de serviços, na alocação dos profissionais e no financiamento. Nesse sentido, não era possível se falar em uma gestão de recursos humanos e, sim, na administração de mais um insumo, ao lado de outros, como os de recursos materiais e financeiros necessários para promover a oferta de ações e serviços de saúde. Nas décadas de 1980 e 1990, uma nova discussão é aberta, na qual essa visão do trabalho e do trabalhador é relocada, permitindo que planejamento e qualificação do trabalho e do trabalhador sejam repensados, e uma nova agenda para os gestores da saúde seja proposta (Conselho Nacional de Secretários de Saúde, 2007).

Em 2003, com a criação da Secretaria da Gestão do Trabalho e da Educação na Saúde (SGETES), no MS, tornou-se possível um deslocamento da concepção tradicional de recursos humanos em saúde, advinda das ciências da administração, para uma concepção mais ampliada e necessariamente integrada acerca da gestão e qualificação do trabalho no SUS. Nesse sentido, diversas temáticas relativas à gestão dos trabalhadores da saúde passaram a ser pautadas: valorização profissional e a regulação das relações de trabalho, que passam pela construção do plano de cargos, carreiras e salários; desprecarização do trabalho; mesa de negociação permanente; estratégia de educação permanente; avaliação de desempenho; e incentivos à produtividade (Vieira, 2008).

Considerando sua complexidade, faz-se necessário trazer para o debate a gestão do trabalho e da educação na saúde como política pública. Nesse sentido, a SGETES trouxe uma mudança positiva para a política de recursos humanos. Ao considerá-la como uma política de Estado, a participação do trabalhador passou a ser fundamental para a efetividade e a eficiência do SUS, como um sujeito transformador de seu ambiente e não apenas um recurso humano realizador de tarefas previamente estabelecidas pela administração local (Machado, 2008).

O processo de gestão do SUS lida com alguns nós críticos como a falta de gestão profissionalizada (persistência do amadorismo); o exercício das múltiplas e complexas tarefas relacionadas com a condução do sistema (tecnologias de gestão); a persistência de clientelismo político na indicação dos ocupantes dos cargos e funções de direção; o engessamento do processo de gestão de serviços e recursos (limitações legais); a dificuldade de articulação intersetorial e o controle social (Cecílio et al., 2007; Paim e Teixeira, 2007).

A gestão do SUS parece, portanto, apontar para a necessidade de qualificação de gestores e de profissionais, visando ao exercício de práticas comprometidas com a sua consolidação. Há necessidade de um investimento redobrado na formação de sujeitos qualificados para atuar em diversos 
espaços e níveis de gestão e de condução política do sistema, com compromisso político com o processo de Reforma Sanitária e a defesa do SUS democrático (Paim e Teixeira, 2007).

A formação e a qualificação dos profissionais para atuar no setor saúde não podem ser empreendidas sem levar em consideração a formação que lhes é oferecida na graduação, o que, para Campos (2006), é um dos obstáculos à mudança do modelo de atenção do SUS. Para este autor, a graduação na área da saúde tem seu foco no referencial positivista, centrado no orgânico, com algumas pitadas de prevenção e promoção e voltada para a atuação no hospital, no laboratório de apoio ao hospital ou no consultório particular.

Com esse enfoque, as instituições de ensino superior tendem a promover a desarticulação entre a produção de conhecimento e o ambiente de trabalho. E muitas vezes apresentam os conteúdos como contraditórios e incompatíveis: objetividade e subjetividade, individual e coletivo, saúde e doença, clínica e saúde pública. Porém, a formação profissional também ocorre no ambiente de trabalho (com os próprios colegas) e com as outras profissões (Campos, 2006).

A aprendizagem profissional abrange, portanto, várias dimensões: a dimensão da aquisição de conhecimento formal (teórico); a dimensão da prática profissional e a dimensão da relação, da troca de experiências e de conhecimento técnico dentro da equipe. Nesse sentido, a educação na saúde precisa considerar essas dimensões no momento de pensar políticas e ofertas de formação e qualificação para o setor.

No âmbito da gestão da educação na saúde, o debate gira em torno de dois paradigmas, denominados 'educação continuada' e 'educação permanente'. A educação continuada (EC) adota o modelo escolar e acadêmico para promover a capacitação dos profissionais da saúde com fins de atualização (Davini, 2009). O enfoque da educação permanente (EP) se apoia no conceito de 'ensino problematizador', que considera que a produção de conhecimento ocorre no cotidiano das instituições de saúde, tendo como base os problemas vivenciados pelos diferentes atores (profissionais, gestores, usuários) (Ceccim e Ferla, 2008). Os espaços educativos são ampliados para incluir as organizações, a comunidade, os clubes e associações comunitárias, permitindo assim que os profissionais (atores reflexivos) construam alternativas de ação e de conhecimento e se articulem com o trabalho em saúde (Davini, 2009).

No campo da capacitação dos profissionais da saúde, persiste o enfoque centrado na transmissão de conhecimento por meio de aulas. Educação permanente e educação continuada são enfoques que podem ser escolhidos mediante uma prévia avaliação de sua pertinência com os objetivos a serem alcançados com os processos formativos e, portanto, podem ser complementares (Arruda et al., 2008). Não dá para apoiar uma política de pessoal 
para o SUS somente na educação no trabalho. Os cursos de média ou longa duração, como os de especialização em saúde pública e os das áreas técnicas, também são necessários. O desafio é combinar a educação no trabalho, a discussão de casos e estudos temáticos com a formação mais estruturada (Campos, 2006).

Pode-se perceber, portanto, que na gestão da educação na saúde a produção de conhecimento também ocorre no cotidiano do trabalho em saúde, envolvendo profissionais, gestores, usuários, comunidade. Os profissionais são considerados atores reflexivos com capacidade de propor soluções e inovações na assistência e gestão da saúde. E os processos de formação dos profissionais são pensados levando-se em consideração as necessidades identificadas na prática dos serviços e a sua implementação, realizada por meio de metodologias de ensino-aprendizagem que incluem tanto a problematização dos processos e vivências do cotidiano como a produção científica (reflexão teórica) sobre a prática.

Todas essas mudanças conceituais ocorridas no âmbito da formação dos trabalhadores dos recursos humanos em saúde apontam para a necessidade de um arcabouço teórico-conceitual para a gestão da educação na saúde capaz de dar conta dos desafios representados pela gestão do SUS. Cabe, portanto, interrogar a produção científica e o marco normativo quanto à forma como têm concebido a questão da formação de profissionais e gestores, utilizando-se, para tanto, quatro perguntas norteadoras: qual o significado atribuído à formação profissional para a saúde? Qual a mudança de posicionamento proposta para o profissional da saúde? Qual a opção teórico-conceitual proposta? Qual a forma de implementar as mudanças na educação na saúde proposta?

Essas transformações conceituais ocorridas na gestão da educação na saúde desafiam todos os atores da saúde (profissionais, gestores e instituições formadoras) a realizar novas opções teórico-conceituais para dar suporte a uma prática mais reflexiva sobre a realidade e os processos de trabalho nos serviços de saúde. Trazem, portanto, uma demanda de ruptura com posicionamentos teóricos que desvinculam teoria e prática nos processos de formação para a atuação profissional, bem como uma mudança de posicionamento subjetivo no sentido de superar uma posição de 'recurso humano' como um realizador de tarefas para uma posição de sujeito que reflete sobre a sua realidade e os processos de trabalho.

Considerando a necessidade de legitimação e consolidação do sistema de saúde brasileiro, o objetivo deste artigo é identificar as concepções teórico-conceituais referentes à gestão da educação na saúde na produção científica e normativa, no período de 2003 a 2009. 


\section{Procedimentos metodológicos}

O caminho utilizado neste estudo4 foi a revisão sistemática de literatura da produção científica, a respeito da educação na saúde e do marco normativo que orientaram a política da gestão da educação na saúde no Brasil, no período de 2003 a 2009.

A revisão sistemática de literatura constitui-se numa revisão planejada para responder a uma pergunta específica, utilizando-se de métodos claros e sistemáticos para identificar, selecionar, avaliar e analisar criticamente os estudos incluídos na revisão. Esse processo de revisão ocorre seguindo uma estruturação previamente determinada para evitar viés no transcorrer da realização de cada uma de suas etapas (Castro, 2001).

O desenvolvimento das etapas de uma revisão sistemática requer, inicialmente, uma definição clara do objeto de interesse a ser investigado. Após essa definição, elaboram-se os critérios que definirão a inclusão ou a exclusão dos artigos a serem explorados na revisão, constituindo-se no desenho do teste de relevância. Em seguida, é feita a escolha do banco de dados e dos descritores a serem utilizados para a captação das publicações existentes. Uma vez realizado esse levantamento, é aplicado o primeiro teste de relevância, que se constitui na leitura dos resumos, permitindo que os primeiros artigos sejam rejeitados ou aceitos (de forma preliminar) para posterior leitura criteriosa do texto completo. Essa leitura permite que novos artigos sejam rejeitados ou aceitos, agora, de forma definitiva. Os artigos aceitos, definitivamente, irão compor o conjunto final de trabalhos para inclusão, e cada um receberá um número identificador único. Os resultados dessa análise podem ser apresentados de forma qualitativa quando, nos estudos incluídos, não é possível uma análise estatística deles (Muñoz et al., 2002).

Com a definição do problema, foi elaborado o desenho do teste de relevância composto dos critérios de inclusão e exclusão. Nesse sentido, considerando os objetivos da pesquisa, definiram-se como critérios de inclusão: artigos em língua portuguesa, relacionados à educação na saúde e gestão da educação na saúde, publicados no período entre 2003 e 2009 e avaliados pelo programa Qualis com classificação A ou B. Como critérios de exclusão: artigos que, apesar de fazerem referência ao objeto da pesquisa, estivessem voltados para a formação clínica do profissional médico e de outros profissionais da saúde; para metodologias de ensino-aprendizagem; para a formação de conselheiros para atuar no controle social e títulos que estivessem presentes em mais de um dos descritores utilizados na busca à base de dados.

Para o levantamento de dados, foi escolhida a base eletrônica do SciELO, uma biblioteca eletrônica que abrange uma coleção selecionada de periódicos científicos brasileiros, e como descritores: educação permanente em 
saúde; educação continuada; educação permanente; educação dos profissionais de saúde e gestão da educação na saúde.

Nessa etapa, identificaram-se 826 artigos, os quais tiveram seus resumos analisados, sendo aplicado o primeiro teste de relevância, por meio do qual 793 artigos foram rejeitados e 33 aceitos preliminarmente. Estes foram lidos na íntegra e então aplicou-se o segundo teste de relevância, resultando em 17 rejeições e 16 aceitações definitivas.

Para a leitura e a análise de cada artigo incluído na revisão, além de seguir a sequência do ano de publicação, foram utilizadas as quatro perguntas norteadoras citadas anteriormente, com o objetivo de contribuir para a identificação das escolhas teórico-conceituais de seus autores, no embasamento da concepção da educação na saúde: 1) Qual o significado atribuído à formação profissional para a saúde? 2) Qual a mudança de posicionamento proposta para o profissional da saúde? 3) Qual a opção teórico-conceitual proposta? 4) Qual a forma de implementar as mudanças na educação na saúde? Ao final da leitura de cada artigo, foi-lhes atribuído um número, para facilitar a sua identificação e posterior análise (Quadro 1). As evidências encontradas como respostas a cada uma das perguntas norteadoras foram sistematizadas, e seus resultados apresentados qualitativamente.

Quadro 1

\begin{tabular}{|c|c|c|c|}
\hline \multicolumn{4}{|c|}{ Identificação dos artigos selecionados para a revisão } \\
\hline No & Autor & $\mathrm{N}^{\circ}$ & Autor \\
\hline A1 & Pereira, 2003 & A9 & Girade, Cruz e Stefanelli, 2006 \\
\hline A2 & Ceccim e Feuerwerker, 2004 & A10 & Franco, 2007 \\
\hline A3 & Mancia, Cabral e Koerich, 2004 & A11 & Ceccim, 2007 \\
\hline A4 & Amâncio Filho, 2004 & $\mathrm{~A} 12$ & Oliveira, 2007 \\
\hline A5 & Merhy, 2005 & A13 & Backes et al., 2007 \\
\hline A6 & Ceccim, 2005a & A14 & Besen et al., 2007 \\
\hline A7 & Ceccim, 2005b & A15 & Ciconet, Marques e Lima, 2008 \\
\hline A8 & Tavares, 2006 & A16 & Peduzzi et al., 2009 \\
\hline
\end{tabular}

Fonte: As autoras. 
Para a revisão sistemática de literatura do marco normativo (portarias), no mesmo período, foi elaborado também um desenho para o teste de relevância. Como critério de inclusão, estabeleceram-se as portarias cujas resoluções estivessem relacionadas a diretrizes e ao desenvolvimento de processos de formação e de reorientação dos profissionais da saúde. Como critérios de exclusão, os conteúdos relacionados foram: definição de recursos financeiros para implementação de políticas; orientações e diretrizes técnico-administrativas para a execução de programas; homologação de resultados de processos seletivos de projetos; instituição de comissões, seus membros e sua forma de funcionamento; certificação de unidades hospitalares como hospitais de ensino.

O levantamento dos dados foi realizado no site do MS, na página da SGETES, que disponibiliza a legislação que subsidia a gestão da educação no SUS para o período estabelecido (2003 a 2009). Foram identificadas 53 portarias ministeriais. Com base na leitura dos títulos, aplicou-se o primeiro teste de relevância, por meio do qual 30 portarias foram rejeitadas e 23 aceitas preliminarmente. As portarias aceitas tiveram seus conteúdos analisados na íntegra, tornando possível a aplicação do segundo teste de relevância, resultando em 18 rejeições e seis aceitações definitivas.

A análise das portarias selecionadas seguiu as mesmas orientações utilizadas na análise dos artigos: leitura, obedecendo à sequência do ano de publicação e com as mesmas perguntas norteadoras, com o objetivo de identificar as mudanças no marco normativo que orientaram a política da gestão da educação em saúde.

\section{Resultados e discussão}

$\mathrm{Na}$ análise dos artigos selecionados, observou-se que, dos 16 artigos analisados, dez abordaram o tema da educação na saúde mediante a escolha teórico-conceitual da educação permanente em saúde (EPS) para embasar a formação dos profissionais para o SUS (Quadro 2). Dentre esses, sete artigos fizeram referência à Política Nacional de Educação Permanente em Saúde proposta pelo MS, em 2004, como estratégia do SUS para a formação e o desenvolvimento de trabalhadores. 
Quadro 2

Produção teórico-conceitual, segundo o posicionamento dos autores acerca da educação na saúde,

e o marco normativo que orientou a Política da Gestão da Educação em Saúde, 2003 a 2009.

\begin{tabular}{|c|c|c|c|c|c|c|c|}
\hline & 2003 & 2004 & 2005 & 2006 & 2007 & 2008 & 2009 \\
\hline $\begin{array}{c}\text { EDUCAÇÃO } \\
\text { NA SAÚDE } \\
\text { Produção científica } \\
\text { (Posicionamentos } \\
\text { dos autores) }\end{array}$ & 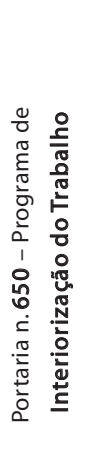 & 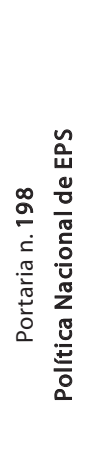 & 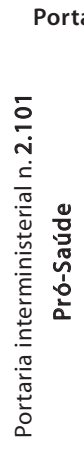 & as mini & 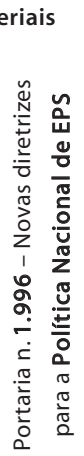 & 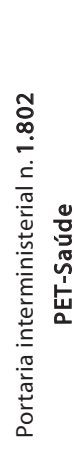 & 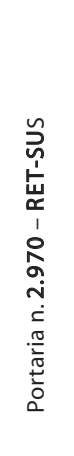 \\
\hline Educação permanente em saúde (EPS) & & $\begin{array}{l}\mathrm{A} 2 \\
\mathrm{~A} 3\end{array}$ & $\begin{array}{l}\text { A5 } \\
\text { A6 } \\
\text { A7 }\end{array}$ & A8 & $\begin{array}{l}\text { A10 } \\
\text { A11 } \\
\text { A14 }\end{array}$ & A15 & \\
\hline Educação continuada (EC) & & & & A9 & & & \\
\hline Educação a distância + EPS & & & & & $\mathrm{A} 12$ & & \\
\hline Educação a distância + EC & & & & & A13 & & \\
\hline Formação profissional contínua & A1 & A4 & & & & & \\
\hline EPS e EC como complementares & & & & & & & A16 \\
\hline
\end{tabular}

Fonte: As autoras.

O MS, em 2004, assumiu o desafio de instituir a Política Nacional de Educação Permanente em Saúde como estratégia do SUS para a formação e o desenvolvimento de trabalhadores para o setor. Apesar de o foco de atuação ser o da educação na saúde, o governo federal assumiu um desafio mais amplo: o da transformação e qualificação da atenção à saúde; da organização das ações e dos serviços; das práticas de saúde; das práticas pedagógicas e dos processos formativos (portaria n. 198/04, anexo II) (Brasil, 2004). O que nos leva a crer que essa política coloca a formação dos profissionais da saúde como central para as transformações, o desenvolvimento e a consolidação do SUS. 
A proposta da política nacional do MS foi a de que os processos de formação dos trabalhadores da saúde se dariam por meio da EP, desenvolvida com bases locorregionais, transformando toda a rede de gestão e de serviços em ambientes-escola. A EP, definida como 'aprendizagem no trabalho', propôs que os processos de capacitação dos trabalhadores tomassem como referência as necessidades de saúde das pessoas, das populações, da gestão setorial e do controle social em saúde. Propôs também que tivessem como objetivo a transformação das práticas profissionais e da própria organização do trabalho e fossem estruturados mediante a problematização do processo de trabalho (portaria n. 198/04, anexo II) (Brasil, 2004).

Esse posicionamento vai ao encontro do outro, muito presente nos processos de formação do profissional para a saúde: o da capacitação e atualização programadas. Essas programações são geralmente demandadas pelos próprios profissionais em razão do que sentem como necessidade de aprendizagem, e são pensadas na lógica da transmissão de conhecimentos técnicos específicos de cada profissão. Apresentam conteúdos focados nos aspectos biológicos do processo saúde-doença, que só posteriormente serão aplicados na rede de atenção à saúde.

A EPS propõe romper com essa lógica de compra de produtos e procedimentos educacionais. Coloca o SUS como um interlocutor nato das escolas na formulação e implementação dos projetos político-pedagógicos de formação, e não mero campo de estágio ou aprendizagem prática (portaria n. 198/04, anexo II) (Brasil, 2004).

Para a implementação da Política Nacional de Educação Permanente em Saúde, as três esferas de gestão passam a ter como desafio descentralizar o debate e a gestão da educação na saúde (instâncias interinstitucionais e locorregionais) mediante a noção de gestão colegiada, perspectiva que provoca o rompimento de uma gestão da formação verticalmente imposta, com base nas proposições de programas nacionais (implicando gestores municipais e estaduais), ao mesmo tempo que possibilita o protagonismo de todos os envolvidos na gestão da formação dos trabalhadores da saúde.

\section{Significado atribuído à formação profissional para a saúde}

O campo da formação profissional se situa como uma das práticas indutoras ao avanço do Movimento pela Reforma Sanitária e concretização do SUS. E, como tal, precisa ser compreendido e gerido como uma atividade central e finalística à formulação de políticas de atenção à saúde e não mais como uma atividade-meio. Essa perspectiva torna possível a implementação de processos com capacidade de transformação das práticas profissionais existentes e com impacto no ensino, na gestão setorial, nas práticas de atenção e no controle social em saúde (Ceccim, 2005a; Merhy, 2005). 
A educação dos profissionais de saúde engloba, além do adequado conhecimento do SUS, aspectos de produção de habilidades técnicas, de pensamento e produção de subjetividade. Nesse sentido, o processo de ensino-aprendizagem se dá não somente por meio da transferência de conteúdos técnicos, normas e protocolos; é preciso incluir a bagagem teórico-conceitual dos trabalhadores, bem como as suas experiências no exercício profissional, seus valores, atitudes e significações pessoais (Ceccim e Feuerwerker, 2004; Ciconet, Marques e Lima, 2008).

A Política Nacional de Educação Permanente em Saúde é uma prática em experimentação e com uma exigência política de ofertar propostas de transformação das práticas profissionais mediante a problematização do processo de trabalho. Proposta coerente com os desafios de formar recursos humanos para o SUS; de implantar, no país, uma gestão do trabalho e da educação com vigor de política pública comprometida com a formação e o desenvolvimento profissional; e de superar as políticas de educação profissional voltadas para o trabalho na indústria, historicamente implementadas no Brasil. Isso desencadeia novos perfis de trabalhadores e de gestores de ações, serviços e sistemas de saúde (Ceccim e Feuerwerker, 2004; Mancia, Cabral e Koerich, 2004; Tavares, 2004, apud Tavares, 2006).

A educação na saúde vem sendo desenvolvida por um amplo investimento institucional, disparado a partir do MS, mas com baixo impacto desses programas na prática cotidiana de produção do cuidado. A Estratégia Saúde da Família (ESF) sofre as consequências de uma formação profissional voltada para a lógica das doenças e tentativas de mudança de comportamento dos indivíduos, conformando uma relação vertical e impositiva. Tornando-se uma de suas problemáticas centrais, esses profissionais demonstram pouco preparo para o trabalho na lógica da promoção da saúde. Tais falas demonstram que a compra de serviços educacionais também não tem servido às mudanças necessárias à formação dos trabalhadores para atuar no SUS. As instituições de ensino também vêm falhando no seu compromisso com a sociedade e com a reorientação dos cursos de formação para sua efetiva apropriação pelo SUS (Franco, 2007; Bensen et al., 2007; Ceccim, 2005b).

Alguns autores concebem a formação profissional de uma forma que se assemelha ora com as concepções presentes na EPS, ora com as concepções da EC. Contudo, utilizam expressões como: formação profissional voltada para o trabalho; atualização constante do profissional de saúde; aquisição contínua de conhecimento; atividades de educação permanente; formação profissional contínua (Pereira, 2003; Amâncio Filho, 2004). Outra concepção, no entanto, considerou estas duas posições (EPS e EC) como concepções complementares (Peduzzi et al., 2009), enquanto apenas um artigo fez referência à EC para o embasamento da formação dos trabalhadores (Girade, Cruz e 
Stefanelli, 2006). Ainda que de forma reduzida, a EPS e a EC foram também vinculadas à estratégia da educação a distância (EAD).

Para Amâncio Filho (2004) e Peduzzi e colaboradores (2009), o Movimento da Reforma Sanitária Brasileira, ao defender um conceito mais ampliado de saúde, aponta a necessidade urgente da melhoria dos processos de formação dos profissionais (qualificação, treinamento e atualização) para atuar na gestão, sustentando e garantindo, técnica e politicamente, a permanência do sistema de saúde. Na assistência, indica também a necessidade de se superar a formação centrada no paradigma biologicista focado na doença. A atuação dos trabalhadores da saúde precisa buscar e acessar constantes espaços de reflexão sobre a prática, a atualização técnico-científica e o diálogo com usuários (população) e demais trabalhadores que integram os serviços.

A crescente acumulação de conhecimentos na área da saúde torna indispensável um processo de formação contínua, com articulação intersetorial entre saúde e educação, voltada para o desenvolvimento de capacidades individuais e coletivas dirigidas aos trabalhadores da saúde (Pereira, 2003; Oliveira, 2007). Quanto às dificuldades de acesso à formação continuada, a EAD apresenta-se como uma estratégia para a EPS. Como inovação pedagógica na educação, o uso da tecnologia pode ser uma opção para manter o profissional estudando e aprendendo dentro da realidade dos serviços de saúde (Backes et al., 2007; Oliveira, 2007).

$\mathrm{Na}$ análise do marco normativo (portarias ministeriais) selecionado, o que se observou, do ponto de vista do significado que é atribuído à formação profissional, foi que, em 2003, com a edição da portaria n. 650/03 (MS) (Brasil, 2003) que aprova as normatizações do Programa de Interiorização do Trabalho em Saúde, a formação foi concebida e implementada de forma vertical, a partir da gerência nacional e estadual, com ênfase no desenvolvimento de conhecimento especializado para atuar nas atividades de atenção básica.

Essa portaria prevê a formação dos profissionais pela modalidade de educação continuada a distância, na forma de ensino em serviço para atuar na ESF. Isso significa que, para os profissionais selecionados, o programa exigia participação no Curso de Especialização em Saúde da Família, na forma de supervisão tutorial contínua pelas instituições de ensino superior (IES) parceiras e pelos Polos de Capacitação em Saúde da Família existentes. Outro aspecto desse programa é que ele foi direcionado somente para médicos e enfermeiros (os profissionais participantes da ESF naquele momento).

Contudo, em 2004, houve uma mudança radical na forma de concepção e implementação da formação profissional para a saúde, representada pela portaria n. 198/2004 (Política Nacional de Educação Permanente em Saúde), que de forma inegável exerceu influência nas portarias editadas posteriormente. 
O significado atribuído à formação profissional para a saúde foi considerado central para o desenvolvimento, a consolidação e principalmente para a transformação das práticas no SUS. Essas transformações se referem ao desenvolvimento de uma concepção de formação para a saúde capaz de incluir tanto a qualificação técnico-científica, que estaria no domínio da habilidade intelectual, quanto o desenvolvimento de habilidade no trabalho em equipes multiprofissionais, que incluem a dimensão da relação interpessoal - criando, dessa forma, condição para uma problematização do processo de trabalho.

\section{Mudança de posicionamento para o profissional da saúde}

Na medida em que a educação dos profissionais da saúde é apresentada como ação finalística e como recurso estratégico para a política de gestão do trabalho e da educação, o que se tem é uma mudança dos trabalhadores da condição de 'recursos' para a de 'atores sociais' das reformas do trabalho. Reformas que se estendem às lutas pelo direito à saúde e pelo ordenamento de práticas acolhedoras e resolutivas de gestão e de atenção à saúde. Quando se está engajado no processo de construção do SUS, devemos nos referir a atores em ação de trabalho, numa prática gerencial libertária e inovadora, e não mais à gestão de recursos humanos ou à gestão de pessoas (Ceccim, 2005a e Ceccim, 2007).

Na condição de atores sociais, a formação para a saúde nos põe diante do desafio de pensar uma nova pedagogia, a pedagogia da implicação, que se assemelha ao desafio dos profissionais de se posicionarem ético-politicamente em discussão (individual e coletivamente) e interrogando também o mundo do trabalho. O não reconhecimento desse saber gerado nessas vivências cotidianas leva à formação de sujeitos heterônomos (grupos sujeitados em lugar de grupos sujeitos), ficando os trabalhadores submetidos a uma pedagogia da dependência (Merhy, 2005; Ceccim, 2007; Franco, 2007).

O tipo de prática de educação que deve ser induzida e construída, nos marcos do debate da EP, tem a ver com o posicionamento de não dissociar a educação em saúde e o trabalho em saúde, na medida em que um termo produz o outro. Seguindo essa concepção, pode-se pensar em outros aspectos, indissociáveis do processo de provocar mudanças no perfil do profissional, como: a reestruturação curricular dos cursos de graduação da área da saúde; a instituição de programas mais amplos de EP que visem articular conhecimento técnico-científico com reflexão crítica sobre o trabalho na rede de saberes, superando práticas educativas a-históricas e acríticas (Amâncio Filho, 2004; Mancia, Cabral e Koerich, 2004; Tavares, 2006; Ciconet, Marques e Lima, 2008; Merhy, 2005).

A educação a distância, como um novo agir na educação, pode vir a contribuir para o desenvolvimento da competência continuada dos profissionais por meio da cooperação, participação, responsabilidade, capacidade decisória 
e de intervenção. Existem fatores estruturais e conjunturais que favoreceram a implantação de políticas, sistemas e programas de EAD, impulsionando o seu crescimento, como os aspectos político-social, econômico, pedagógico e tecnológico (Oliveira, 2007).

A edição da portaria n. 198/04, que institui a Política Nacional de Educação Permanente em Saúde, traz algumas inovações que representam rupturas na forma de conceber a formação dos profissionais para atuarem no SUS. Dentre essas inovações, temos a formação percebida como uma política estratégica do governo federal para a formação e o desenvolvimento do conjunto de profissionais da saúde, em vez de mais um programa pontual do MS. Outra inovação é a que propôs a EP como um conceito pedagógico, no setor da saúde, para efetuar relações orgânicas entre o ensino e as ações e serviços (formação e gestão setorial) e entre a docência e a atenção à saúde (desenvolvimento institucional e controle social). Por último, a forma de implementação da política, que deveria acontecer por meio dos Polos de Educação Permanente em Saúde para o SUS.

Produção científica e marco normativo parecem querer caminhar para a não dissociação entre educação e trabalho, o que exige atores sociais, gestores e profissionais, com clareza das implicações e consequências de sua atuação nas práticas em saúde.

\section{Escolha teórico-conceitual}

A área da saúde requer EP, baseada no pressuposto da aprendizagem significativa (que promove e produz sentidos), e propõe que a transformação das práticas profissionais deve estar apoiada na reflexão crítica sobre as situações vivenciadas pelos profissionais na rede de serviços. Essa rede informa e recria a teoria e a prática (Ceccim e Feuerwerker, 2004).

Nos modelos consolidados de educação no trabalho, programas e sistemas de EP e EC vêm sendo utilizados como conceitos sinônimos, embora o foco do modelo de EC seja a aplicação do conhecimento teórico especializado. Contudo, essa não tem, necessariamente, o potencial de transformar a prática nos serviços, pois trabalha de maneira descontextualizada, sem possibilitar a incorporação de novos conceitos e princípios às práticas estabelecidas (Mancia, Cabral e Koerich, 2004; Ceccim, 2005a).

Apesar de a concepção de EP ter como foco de atuação a aprendizagem significativa no contexto da realidade dos serviços, e a EC o aprendizado intelectual (formal), há quem advogue a complementaridade entre ambas como elemento importante para o desenvolvimento dos trabalhadores na atenção primária à saúde (Peduzzi et al., 2009).

Outros autores propõem a definição de uma linha de produção pedagógica na estrutura organizacional do SUS, capaz de contribuir na produção 
de sujeitos (entendidos como coletivos) com capacidade de intervir na realidade com o objetivo de transformá-la. Nessa perspectiva, uma concepção de formação com o foco exclusivo na EC dificilmente poderia superar a 'pedagogia da dependência' gerada pelas formações centradas apenas no acúmulo de conhecimento teórico e técnico das diferentes especialidades. Acrescentando-se o fato de que não é mais possível sustentar as visões gerenciais de que a baixa eficácia das ações de saúde se deve à falta de competência dos trabalhadores, essa visão gerou muitos cursos compensatórios, que não vem resultando em efeitos positivos e mudanças nas práticas desses profissionais (Franco, 2007; Merhy, 2005).

Considerando o marco normativo com a portaria n. 198/04, a formação e o desenvolvimento dos profissionais para atuar no SUS passaram a ser referenciados nos princípios da EPS, a qual propôs que os processos de capacitação tivessem como objetivo a transformação das práticas profissionais e da própria organização do trabalho, tomando como base: as necessidades de saúde das pessoas e das populações; a gestão setorial; o controle social em saúde e a repactuação das iniciativas de formação para uma condução locorregional - criando, assim, condições para uma Política Nacional de Educação Permanente em Saúde integrada.

A perspectiva da EPS para o embasamento dos processos formativos é mencionada também nas portarias interministeriais n. 2.101/05 (Brasil, 2005) e 1.802/08 (Brasil, 2008). A escolha teórica conceitual talvez precise acompanhar a diversidade de realidades presente nas regiões brasileiras com diferentes demandas. Contudo, se considerarmos a formação profissional como primordial para a consolidação do sistema de saúde nacional, precisamos também fortalecer a Política Nacional de Educação Permanente em Saúde como estratégia do SUS para a formação e o desenvolvimento de trabalhadores para o setor.

\section{Forma de implementação das mudanças na educação na saúde}

Para produzir mudanças de práticas de gestão e de atenção, considerando a velocidade com que conhecimentos e saberes tecnológicos se renovam na área da saúde, é fundamental a interação entre os segmentos da formação, da atenção, da gestão e do controle social em saúde, que conformam o quadrilátero da formação. Essa interação permite dignificar as características locais, valorizar as capacidades instaladas, desenvolver as potencialidades existentes em cada realidade, estabelecer a aprendizagem significativa e a efetiva e criativa capacidade de crítica, bem como produzir sentidos, autoanálise e autogestão (Ceccim, 2005a).

A ordenação da formação para a área da saúde como política pública afirma a perspectiva da construção de espaços locais, microrregionais e 
regionais com capacidade de desenvolver a educação das equipes de saúde, dos agentes sociais e de parceiros intersetoriais para uma saúde de melhor qualidade - lógica que se assemelha à da EP: descentralizadora, ascendente e transdisciplinar (Ceccim e Feuerwerker, 2004).

Portanto, atuar na direção da descentralização de concepções teóricas como a da EPS exige articulações interinstitucionais e locorregionais possíveis de serem viabilizadas pelo que a portaria ministerial n. 198/04 (Brasil, 2004) denominou de Polos de Educação Permanente em Saúde, com capacidade para descentralizar e disseminar capacidade pedagógica na saúde e desenvolver recursos tecnológicos baseados na noção de aprender a aprender e de trabalhar em equipe (constituição de equipes multiprofissionais), na promoção da aprendizagem individual, coletiva e institucional (Ceccim, 2005a, 2005b).

Outro aspecto a ser considerado, quando o foco é a forma de implementação da educação na saúde para o SUS, é o reconhecimento da existência de duas grandes dimensões no campo da educação: a dimensão da 'cognição', que é dada pela capacidade de transferir e produzir conhecimento técnico; e a dimensão da 'subjetivação', que deve ser dada pela capacidade que têm certas pedagogias de promover mudanças na subjetividade. $\mathrm{O}$ trabalhador de saúde opera a sua dimensão cognitiva, a de 'ser' trabalhador dotado de plena capacidade técnica de intervir sobre problemas de saúde. Opera, também, uma dimensão subjetiva, a de 'ser para si e para o outro', conferindo alteridade nos atos de cuidado, em que o outro está sempre presente como sujeito da ação de produzir o cuidado (Franco, 2007).

A ênfase no desenvolvimento da alteridade nos atos de cuidado é importante para a superação de uma visão gerencialista que subestima e rejeita o protagonismo dos trabalhadores, reforçando, neles, o acolhimento das designações de suas corporações profissionais e dos projetos de governo, sem questionamento - tornando-os reféns dos valores, ventríloquos dos teóricos, em vez de bons cuidadores de vidas que pedem atualidade, singularidade, novidade (Ceccim, 2007, apud Cecílio, 2007).

A portaria n. 198/04 (Brasil, 2004), com a implantação dos Polos de Educação Permanente, renomeia os já existentes Polos de Capacitação em Saúde da Família; contudo, acrescenta novas proposições teórico-conceituais ao seu significado e novas atribuições. Esses polos passam a se caracterizar como o meio escolhido pela política para viabilizar a descentralização da formação dos profissionais, mediante uma condução locorregional e coordenação colegiada (colegiados de gestão). A noção de colegiado de gestão coloca todos (União, estados e municípios) como protagonistas do desenvolvimento e da transformação dos processos formativos no setor saúde, superando a lógica hegemônica da verticalidade de comando na condução da política. 
Apesar de não ser uma portaria interministerial, a sua condução se pretende interinstitucional, estimulando a cooperação e a conjunção de esforços no sentido da superação da fragmentação existente nos processos de formação profissional para a saúde presente nas propostas de estados e municípios, compatibilizando-as com o nível federal e contribuindo para o fortalecimento do SUS.

A portaria n. 198/04 (Brasil, 2004) foi alterada, em 2007, pela portaria n. 1.996 (Brasil, 2007a) e instituiu novas diretrizes e estratégias para a implementação da Política Nacional de Educação Permanente em Saúde, adequando-a às diretrizes operacionais e ao regulamento do Pacto pela Saúde.

A condução locorregional da política, seguindo as diretrizes elaboradas pelo Departamento de Gestão da Educação na Saúde (Deges/SGETS), será por meio dos Colegiados de Gestão Regional (CGRs), com a participação articuladora das Comissões Permanentes de Integração Ensino-Serviço (CIESs), que têm o papel de induzir as mudanças, apoiar a elaboração dos Planos Regionais de Educação Permanente em Saúde (PAREPS) e cooperar tecnicamente com eles, e principalmente realizar o acompanhamento, o monitoramento e a avaliação das ações e estratégias de educação implementadas.

Os PAREPS deverão estar coerentes com as orientações presentes nos instrumentos do Sistema de Planejamento do SUS (portaria n. 3.332/2006) (Brasil, 2006) e conter: caracterização da região de saúde e identificação de seus principais problemas de gestão e assistência; caracterização das necessidades de formação; identificação dos atores envolvidos; estabelecimento de metas e indicadores para o acompanhamento, a avaliação e a análise da viabilidade do plano com base nos recursos disponíveis.

Em 2005, o MS identificou a necessidade de reorientar o processo de formação em saúde a partir da graduação, quando editou a portaria n. 2.101/05 (Pró-Saúde) (Brasil, 2005), inicialmente para os cursos de medicina, enfermagem e odontologia, posteriormente ampliando-se para os demais cursos da área da saúde pela portaria interministerial n. 3.019/07 (Brasil, 2007b). Com o Pró-Saúde, o governo federal objetivou oferecer, à sociedade, profissionais habilitados para responder às necessidades da população e à operacionalização do SUS, estabelecendo mecanismos de cooperação entre os gestores do SUS e as escolas de ensino superior, visando à formação dos profissionais - desde a graduação, articulada e integrada com a rede de atenção do SUS - e também à melhoria da atenção e à EP.

O investimento no desenvolvimento da reorientação da formação profissional para a saúde desde a graduação, nos municípios que aderiram à proposta do Pró-Saúde (portaria n. 2.101/05) (Brasil, 2005), pode contribuir para a construção da mudança de posicionamento de estudantes, discentes, instituições de ensino, profissionais e gestores, necessária para a superação de uma formação biologizante, centrada em procedimentos e descontextualizada. 
Em 2008, foi editada a portaria 1.082 (Brasil, 2008), que instituiu o Programa de Educação pelo Trabalho para a Saúde (PET-Saúde), para o fomento a grupos de aprendizagem tutorial nas práticas do SUS. Caracteriza-se como instrumento para viabilizar programas de aperfeiçoamento e especialização em serviço e iniciação ao trabalho, dirigido aos profissionais e aos estudantes da área da saúde, de acordo com as necessidades do SUS.

Em 2009, a portaria n. 2.970 (Brasil, 2009) atualizou a portaria n. 1.298/ 2000 (Brasil, 2000), que instituiu a Rede de Escolas Técnicas e Centros Formadores vinculados ao SUS, a RET-SUS, cujo objetivo era compartilhar conhecimentos, difundir metodologias e recursos tecnológicos para as atividades de ensino, pesquisa e cooperação técnica, tendo em vista a implementação de políticas de educação profissional em saúde, prioritariamente para os trabalhadores do SUS.

Parece que, do ponto de vista da implementação da formação profissional como política de recursos humanos para o SUS, os gestores das três esferas de gestão, as instituições de ensino superior e os profissionais têm diante de si o desafio da viabilização de espaços de gestão colegiada. Esses espaços exigem, além da vivência da prática de compartilhamento de poder, o exercício constante da articulação, da superação das concepções de formação, já bem instituídas e consolidadas, e a incorporação de processos de monitoramento e avaliação das ações desenvolvidas que permitirão ajustes e readequações dos planos regionais.

\section{Considerações finais}

A socialização profissional é um processo de educação moral, interativo e multidirecional entre socializandos e socializadores - estudantes, professores e seus cursos.

No entanto, a presença da EC como aposta teórico-conceitual para o embasamento da formação profissional nos leva a pensar em uma possível resistência a um processo de mudança de posição, intelectual e subjetiva, que a gestão do SUS parece exigir tanto de profissionais como de gestores; ou em uma compreensão equivocada do significado da aposta teórico-conceitual presente na proposta da EPS. Contudo, a percepção de que educação permanente em saúde e EC podem servir ao processo de formação dos profissionais abre a possibilidade de diálogo e, portanto, de entendimento e trabalho em conjunto para a consolidação do sistema de saúde.

Do ponto de vista do marco normativo, o significado atribuído à formação profissional passou por uma mudança radical na forma de sua concepção e implementação, representada pela portaria n. 198/04 (Política Nacional de Educação Permanente em Saúde) (Brasil, 2004), que influenciou as portarias 
editadas posteriormente. Contudo, tal mudança ainda não teve reflexos na prática dos processos de formação profissional para o setor saúde.

Outro aspecto relevante a ser ressaltado é a importância que as dimensões do monitoramento e da avaliação têm no processo de implementação de uma política, na medida em que permitem que os resultados sejam revistos e que possíveis alterações no curso das ações possam ocorrer de forma a se adequarem às realidades locais.

A parceria entre os ministérios da Saúde e da Educação constitui um aspecto importante. Das sete portarias analisadas, três foram instituídas como portarias interministeriais, contribuindo para o processo de reestruturação e fortalecimento da formação profissional, tanto no âmbito da graduação como no da pós-graduação.

As mudanças conceituais na gestão da educação na saúde configuram-se ainda como um desafio para gestores e profissionais, em razão das dificuldades que o processo de implementação na prática da gestão dos sistemas de saúde representa para um sistema da complexidade do SUS.

\section{Colaboradores}

Neuza Buarque de Macêdo, Paulette Cavalcanti de Albuquerque e Kátia Rejane de Medeiros participaram da realização da pesquisa, análise e interpretação dos dados, e da redação do texto. 
Resumen El camino utilizado en este estudio fue la revisión sistemática de literatura de la producción científica y del marco normativo, con el fin de identificar las principales ideas teóricas y conceptuales referidas a la gestión de la educación en salud en Brasil, en el período de 2003 a 2009. La gestión del Sistema Único de Salud señala la necesidad de capacitación de gestores y profesionales para trabajar en el sector desde su graduación, incluyendo la integración entre enseñanza y servicio, y la formación profesional en el ambiente de trabajo. Después de aplicar los criterios de inclusión, 16 artículos y seis ordenanzas fueron incorporados a la revisión. En el ámbito de la gestión de la educación en salud, el debate gira en torno a dos principales concepciones, la educación continua y la educación permanente, centradas respectivamente en el modelo académico y en el aprendizaje en equipo, inherente a los grupos de trabajadores. El análisis de la producción científica y del marco normativo sugiere que las transformaciones conceptuales desafían a todos los actores de la salud para llevar a cabo una ruptura teórica y conceptual, y posicionamiento subjetivo, superando una condición de 'recurso humano', realizador de tareas para un sujeto capaz de reflexionar sobre los procesos de trabajo.

Palabras clave formación de recursos humanos; calificación profesional; gestión en salud.

\section{Notas}

1 Fundação Oswaldo Cruz, Recife, Pernambuco, Brasil.

Mestre em Saúde Pública pelo Centro de Pesquisas Aggeu Magalhães, da Fundação Oswaldo Cruz. <neuzabuarque@gmail.com>

Correspondência: Rua Real da Torre, 292/1.502, Madalena, CEP 50610-000, Recife, Pernambuco, Brasil.

2 Fundação Oswaldo Cruz, Recife, Pernambuco, Brasil.

Doutora em Saúde Pública pelo Centro de Pesquisas Aggeu Magalhães, da Fundação Oswaldo Cruz. <paulette.cavalcanti@gmail.com>

3 Fundação Oswaldo Cruz, Recife, Pernambuco, Brasil.

Doutora em Saúde Pública pelo Centro de Pesquisas Aggeu Magalhães, da Fundação Oswaldo Cruz.<kmedeiros@cpqam.fiocruz.br>

4 Pesquisa realizada para obtenção do título de especialista em Saúde Coletiva do Programa de Residência Multiprofissional em Saúde Coletiva do Departamento de Saúde Coletiva, Centro de Pesquisa Aggeu Magalhães, Fundação Oswaldo Cruz. Os custos desta pesquisa foram financiados pela pesquisadora Neuza Buarque de Macêdo. 


\section{Referências}

AMÂNCIO FILHO, Antenor. Dilemas e desafios da formação profissional em saúde. Interface: Comunicação, Saúde, Educação, Botucatu, v. 8, n. 15, p. 375-380, ago. 2004.

ARRETCHE, Marta. Relações federativas nas políticas sociais. Educação e Sociedade, Campinas, v. 23, n. 80 , p. 25-48, set. 2002.

ARRUDA, Marina P. et al. Educação permanente: uma estratégia metodológica para os professores da saúde. Revista Brasileira de Educação Médica, Rio de Janeiro, v. 32, n. 4, p. 518-524, dez. 2008.

BACKES, Vânia M. S. et al. Competência dos enfermeiros em problematizar a realidade do serviço de saúde no contexto do Sistema Único de Saúde. Texto \& Contexto: Enfermagem, Florianópolis, v. 16, n. 4, p. 727736, dez. 2007.

BESEN, Candice B. et al. A Estratégia Saúde da Família como objeto de educação em saúde. Saúde e Sociedade, São Paulo, v. 16, n. 1, p. 57-68, abr. 2007.

BRASIL. Ministério da Saúde. Portaria n. 1.298, de 28 de novembro de 2000. Institui a Rede de Escolas Técnicas e Centros Formadores vinculados às instâncias gestoras do Sistema Único de Saúde (RET-SUS). Disponível em: <http://dtr2001.saude.gov.br/ sas/PORTARIAS/Port2005/GM/GM-1 168. htm>. Acesso em: 10 fev. 2014.

Ministério da Saúde. Portaria n. 650, de 27 de maio de 2003. Institui o Programa de Interiorização do Trabalho em Saúde. Disponível em: <www.saude.gov. br/saudelegis>. Acesso em: 7 dez. 2009.

Ministério da Saúde. Portaria n. 198, de 13 de fevereiro de 2004. Institui a Política Nacional de Educação Permanente em Saúde como estratégia do Sistema Único de Saúde para a formação e o desenvolvimento de trabalhadores para o setor. Dis- ponível em: <http://dtr2001.saude.gov.br/ sas/PORTARAS/Port2004/GM/GM-198.htm>. Acesso em: 10 fev. 2014.

Ministério da Saúde. Portaria Interministerial n. 2.101, de 3 de novembro de 2005. Institui o Programa Nacional de Reorientação da Formação Profissional em Saúde - Pró-Saúde - para os cursos de graduação em Medicina, Enfermagem e Odontologia. Disponível em: <www.saude.gov. br/saudelegis >. Acesso em: nov. 2009.

Ministério da Saúde. Portaria n. 3.332, de 28 de dezembro de 2006. Aprova orientações gerais relativas aos instrumentos do Sistema de Planejamento do SUS. Disponível em: <www.saude.gov.br/saudelegis>. Acesso em: set. 2009.

Ministério da Saúde. Portaria n. 1.996, de 20 de agosto de 2007a. Estabelece as diretrizes para a implementação da Política Nacional de Educação Permanente em Saúde. Disponível em: <www.saude.gov.br/ saudelegis>. Acesso em: set. 2009.

Ministério da Saúde. Portaria Interministerial n. 3.019, de 26 de novembro de 2007b. Dispõe sobre o Programa Nacional de Reorientação da Formação Profissional em Saúde - Pró-Saúde - para os cursos de graduação da área da saúde. Disponível em: <www.saude.gov.br/saudelegis $>$. Acesso em: nov. 2009.

Ministério da Saúde. Portaria Interministerial n. 1.082, de 26 de agosto de 2008. Institui o Programa de Educação pelo Trabalho para a Saúde - PET-Saúde. Disponível em: <www.saude.gov.br/saudelegis>. Acesso em: nov. 2009.

Ministério da Saúde. Portaria n. 2.970, de 25 de novembro de 2009. Institui a Rede de Escolas Técnicas do SUS (RET-SUS). Disponível em: <www.saude.gov.br/saudelegis>. Acesso em: nov. 2009. 
CAMPOS, Gastão W. S. Políticas de formação de pessoal para o SUS: reflexões fragmentadas. Cadernos RH Saúde, Brasília v. 3, n. 1, p. 52-56, mar. 2006.

CASTRO, Aldemar A. Revisão sistemática e meta-análise. 16 maio 2001. Disponível em: <http://metodologia.org/wp-content/ uploads/2010/08/metal.PDF>. Acesso em: 2 maio 2010.

CECCIM, Ricardo B. Educação permanente em saúde: desafio ambicioso e necessário. Interface: Comunicação, Saúde, Educação, Botucatu, v. 9, n. 16, p. 161-177, set. 2004/fev. 2005a.

Educação permanente em saúde: descentralização e disseminação de capacidade pedagógica na saúde. Ciência \& Saúde Coletiva, Rio de Janeiro, v. 10, n. 4, p. 975986, out./dez. 2005 b.

Um sentido muito próximo ao que propõe a educação permanente em saúde: o devir da educação e a escuta pedagógica da saúde. Interface: Comunicação, Saúde, Educação, Botucatu, v. 11, n. 22, p. 358-361, ago. 2007.

CECCIM, Ricardo B.; FERLA, Alcindo A. Educação permanente em saúde. In: PEREIRA, Isabel B.; LIMA, Julio C. F. Dicionário da educação profissional em saúde. 2. ed. rev. ampl. Rio de Janeiro: EPSJV, 2008. p. 162-168.

CECCIM, Ricardo B.; FEUERWERKER, Laura C. M. O quadrilátero da formação para a área da saúde: ensino, gestão, atenção e controle social. Physis: Revista de Saúde Coletiva, Rio de Janeiro, v. 14, n. 1, p. 4165, jun. 2004.

CECÍLIO, Luiz C. O. et al. O gestor municipal na atual etapa de implantação do SUS: características e desafios. Reciis: Revista Eletrônica de Comunicação, Informação e Inovação em Saúde, Rio de Janeiro, v. 1, n. 2, p. 200-207, jul.-dez. 2007. Disponível em: $<$ www.reciis.icict.fiocruz.br/index.php/ reciis/article/viewFile/84/79 > . Acesso em: 7 fev. 2014 .
CICONET, Rosane M.; MARQUES, Giselda Q.; LIMA, Maria A. D. da S. Educação em serviço para profissionais de saúde do Serviço de Atendimento Móvel de Urgência (Samu): relato da experiência de Porto Alegre-RS. Interface: Comunicação, Saúde, Educação, Botucatu, v. 12, n. 26, p. 659-666, set. 2008 .

CONSELHO NACIONAL DE SECRETÁRIOS DE SAÚDE (CONASS). Gestão do trabalho na saúde. Brasília: Conass, 2007 (Coleção Progestores - Para entender a gestão do SUS, 5).

DAVINI, Maria C. Enfoques, problemas e perspectivas na educação permanente dos recursos. In: BRASIL. Ministério da Saúde. Política Nacional de Educação Permanente em Saúde. Brasília: Ministério da Saúde, 2009. p. 39-58. (Série B. Textos Básicos de Saúde).

DUSSAULT, Gilles. A gestão dos serviços públicos de saúde: características e exigências. Revista de Administração Pública, Rio de Janeiro, v. 26, n. 2, p. 8-19, abr.-jun. 1992.

FRANCO, Túlio Batista. Produção do cuidado e produção pedagógica: integração de cenários do sistema de saúde no Brasil. Interface: Comunicação, Saúde, Educação, Botucatu, v. 11, n. 23, p. 427-438, dez. 2007.

GIRADE, Maria G; CRUZ, Emirene M. N. T.; STEFANELLI, Maguida C. Educação continuada em enfermagem psiquiátrica: reflexão sobre conceitos. Revista da Escola de Enfermagem da USP, São Paulo, v. 40, n. 1, p. 105-110, mar. 2006.

MACHADO, Maria H. Gestão do trabalho em saúde. In: PEREIRA, Isabel B.; LIMA, Julio C. F. Dicionário da educação profissional em saúde. 2.ed. rev. ampl. Rio de Janeiro: EPSJV, 2008. p. 227-231.

MANCIA, Joel R.; CABRAL, Leila C.; KOE$\mathrm{RICH}$, Magda S. Educação permanente no contexto da enfermagem e na saúde. Revista Brasileira de Enfermagem, Brasília, v. 57, n. 5, p. 227-231, out. 2004. 
MERHY, Emerson E. O desafio que a educação permanente tem em si: a pedagogia da implicação. Interface: Comunicação, Saúde, Educação, Botucatu, v. 9, n. 16, p. 172-174, fev. 2005.

MUÑOZ, Susana I. et al. Revisão sistemática da literatura e metanálise: noções básicas sobre seu desenho, interpretação e aplicação na área de saúde. In: SIMPÓSIO BRASILEIRO DE COMUNICAÇÃO EM ENFERMAGEM, 8, 2002, Universidade de São Paulo, Ribeirão Preto. Anais. Disponível em: <http://www.proceedings.scielo.br/scielo. php?pid=MSC0000000052002000200010\& script $=$ sci_abstract $\&$ tlng $=$ pt $>$. Acesso em: jan. 2010.

OLIVEIRA, Marluce A. N. Educação a distância como estratégia para a educação permanente em saúde: possibilidades e desafios. Revista Brasileira de Enfermagem, Brasília, v. 60 , n. 5, p. 585-589, out. 2007.

PAIM, Jairnilson S.; TEIXEIRA, Carmen F. Configuração institucional e gestão do Sistema Único de Saúde: problemas e desafios. Ciência \& Saúde Coletiva [on line], v. 12, supl., p. 1.819-1.829, 2007. Disponível em: <http://www.scielo.br/scielo.php?pid= S1413-81232007000700005\&script $=$ sci_ arttext>. Acesso em: set. 2008.
PEDUZZI, Marina et al. Atividades educativas de trabalhadores na atenção primária: concepções de educação permanente e de educação continuada em saúde presentes no cotidiano de unidades básicas de saúde em São Paulo. Interface: Comunicação, Saúde, Educação, Botucatu, v. 13, n. 30, p. 121134, set. 2009.

PEREIRA, Adriana L. F.. As tendências pedagógicas e a prática educativa nas ciências da saúde. Cadernos de Saúde Pública, Rio de Janeiro, v. 19, n. 5, p. 1.527-1.534, out. 2003.

PIERANTONI, Celia R. As reformas do Estado, da saúde e recursos humanos: limites e possibilidades. Ciência \& Saúde Coletiva, Rio de Janeiro, v. 6, n. 2, p. 341-360, 2001.

TAVARES, Cláudia M. M. A educação permanente da equipe de enfermagem para o cuidado nos serviços de saúde mental. Texto \& Contexto: Enfermagem, Florianópolis, v. 15, n. 2, p. 287-295, jun. 2006.

VIEIRA, Monica. Recursos humanos em saúde. In: PEREIRA, Isabel B.; LIMA, Julio C. F. Dicionário da educação profissional em saúde. 2. ed. rev. ampl. Rio de Janeiro: EPSJV, 2008. p. 343-347.

Recebido em 16/03/2011

Aprovado em 24/09/2013 